\title{
Age at onset of first episode and time to treatment in in-patients with bipolar disorder
}

\author{
Gunnar Morken, Arne E. Vaaler, Gunn E. Folden, Ole A. Andreassen and Ulrik F. Malt
}

\section{Summary}

This study aimed to investigate the relationship between age at onset and time to first pharmacological treatment in patients with either bipolar I or II disorder. A total of 146 consecutive in-patients acutely admitted from the same catchment area were included. Patients were divided into four age groups: 0-12 years (23\%); 13-18 years (32\%); 19-29 years $(26 \%)$; and $\geqslant 30$ years $(18 \%)$. Mean age at first affective episode was 20.2 years $(s . d .=11.8)$. This represents a similar pattern to the age at onset seen in out-patients in the USA. Early age at onset predicted a longer time to first pharmacological treatment $(\rho=-0.695, P<0.01)$.

\section{Declaration of interest}

None.
An early age at onset of the first affective episode in bipolar disorder has been associated with poor prognosis, rapid cycling, substance misuse and a long duration between the first affective episode and the first treatment. ${ }^{1-7}$ Although the distribution of age at onset seems to be the same in different samples from the USA, ${ }^{1,5}$ patients from Europe are reported to be older when they have their first episode. ${ }^{1}$ The aim of our study was to describe age at onset of the first depressive or hypomanic/manic episode and the corresponding time to first treatment and to first hospital admission in consecutive, acutely admitted patients with either bipolar I or II disorder in a department receiving all admittances in a catchment area.

\section{Method}

The acute ward of the Østmarka Department of Psychiatry, St Olavs University Hospital, Trondheim, Norway, has a catchment area of 140000 inhabitants. Norwegian acute psychiatric services are available to everyone and acute admission to other psychiatric hospitals occurs only when inhabitants temporarily reside outside of the catchment area. The Department is a partner of the Bipolar Research And Innovation Network - Norway (BRAIN).

Consecutive patients admitted to the hospital between November 2002 and September 2007 with current or past hypomania, mania, mixed episodes or depression were diagnosed by the Structured Clinical Interview for the DSM-IV (SCID-1). ${ }^{8,9}$ All patients with either bipolar I or II disorders were included. No exclusion criteria existed. All diagnoses were confirmed in a weekly consensus meeting where at least two senior psychiatrists with expertise in SCID, at least one of whom knew the patient, participated. The patients were interviewed with a Norwegian adaptation of the Network Entry Questionnaire used by the Bipolar Collaboration Network $(\mathrm{BCN})^{10,11}$ where age at onset is defined as 'their first depressive symptoms associated with dysfunction (a definition that would be likely to meet DSM-IV criteria), as well as their first hypomanic or manic symptoms similar to those experienced in adulthood. ${ }^{1,3}$ Information was also collected from the patients' families and records. First pharmacological treatment for depression or hypomania/mania and age at first admission to a psychiatric department for an affective episode were recorded. Psychosis was defined as lifetime admission to hospital with a psychotic illness. The patients were divided into four groups according to age at onset, defined much as in the $\mathrm{BCN}^{1,3}$ and the Systematic Treatment Enhancement Program for
Bipolar Disorder (STEP-BD): ${ }^{5}$ childhood ( $0-12$ years); adolescent (13-18 years); young adult (19-29 years); and adult ( $\geqslant 30$ years). The STEP-BD combined the two older groups. Written, informed consent was obtained from all participants. The study was approved by the Regional Committee for Research Ethics, Middle Norway.

Categorical variables were analysed with chi-squared tests. Continuous measures were examined using one-way analyses of variance (ANOVA) with the four age groups. The Tamhanes test for equal variances not assumed was used post hoc for comparisons between groups. The results were confirmed with the KruskalWallis test for the four age groups. Correlations were done using Spearman's rho correlation test.

\section{Results}

Demographic and clinical characteristics for the four age groups are presented in Table 1 and online Table DS1.

The duration from onset to first pharmacological treatment $(\rho=-0.695, P<0.01)$ and the duration from onset to first admission to hospital $(\rho=-0.677, P<0.01)$ were inversely correlated with age at onset.

Patients with lifetime psychosis were younger at first treatment (mean $27.6 v$. 31.2 years, $P=0.050$ ) and first admission to hospital (29.2 v. 35.8 years, $P<0.001)$ and had shorter time to first treatment $(7.2 v .10 .9$ years, $P=0.038)$ and to first admission to hospital ( 8.9 v. 15.7 years, $P=0.001$ ). Patients with rapid cycling were younger at first episode (15.4 v. 21.7 years, $P=0.005)$ and at first treatment $(25.2$ years $v .30 .5$ years, $P=0.016)$ and had shorter time to first admission (8.9 v. 15.7 years, $P=0.001)$. Patients with bipolar I disorder were younger at first admission (30.5 v. 36.3 years, $P=0.024$ ) and had a shorter time from first episode to first admission (10.7 v. 16 years, $P=0.015)$ than patients with bipolar II disorder.

\section{Discussion}

The proportion of patients with childhood onset was similar $(23 \%)$ to that in the STEP-BD study from the USA $(27.7 \%)^{5}$ and from US centres of the BCN study $(22 \%),{ }^{1}$ but differed from European centres (The Netherlands and Germany) of the same BCN study (2\%). ${ }^{1}$

The mean age at first treatment was 26 years among patients with onset before 30 years of age. This finding is similar to that 
Table 1 Demographics of patients with bipolar disorder of childhood, adolescent, young adult and adult onset

\begin{tabular}{|c|c|c|c|c|c|c|c|}
\hline & $\begin{array}{l}\text { Childhood } \\
\text { (0-12 years) }\end{array}$ & $\begin{array}{l}\text { Adolescent } \\
\text { (13-18 years) }\end{array}$ & $\begin{array}{l}\text { Young adults } \\
\text { (19-29 years) }\end{array}$ & $\begin{array}{c}\text { Adults } \\
(\geqslant 30 \text { years })\end{array}$ & $\begin{array}{c}\text { Total } \\
\text { sample }\end{array}$ & $F$ & $P$ \\
\hline Patients, $n$ (\%) & $34(23)$ & $47(32)$ & $38(26)$ & $27(18)$ & 146 & & \\
\hline Age at index admission, years: mean (s.d.) & $39.6(13.1)$ & $38.6(14.3)$ & $38.6(11.9)$ & $52.9(10.3)$ & $41.5(13.7)$ & 9.02 & $<0.001 * *$ \\
\hline Age at onset of first episode, years: mean (s.d.) & $8.0(2.3)$ & $15.3(1.7)$ & $22.2(3.0)$ & $41.3(7.0)$ & $20.2(11.8)$ & 459.1 & $<0.001 *$ \\
\hline Age at first treatment, years: mean (s.d.) & $26.6(8.8)$ & $26.4(10.8)$ & $25.8(6.6)$ & $42.7(7.1)$ & $29.4(10.8)$ & 25.1 & $<0.001 * *$ \\
\hline Time to first treatment, years: mean (s.d.) & $18.6(8.8)$ & $11.1(11.2)$ & $3.5(5.5)$ & $1.7(3.7)$ & $9.0(10.3)$ & 27.4 & $<0.001^{* \star *}$ \\
\hline Age at first admission, years: mean (s.d.) & $32.2(10.1)$ & $29.5(11.8)$ & $28.2(8.3)$ & $44.0(7.8)$ & $32.5(11.4)$ & 15.9 & $<0.001 * *$ \\
\hline Time to first admission, years: mean (s.d.) & $24.2(10.5)$ & $14.2(11.9)$ & $6.0(7.9)$ & $2.7(4.4)$ & $12.3(12.3)$ & 32.8 & $<0.001^{* * * *}$ \\
\hline
\end{tabular}

of the BCN study (estimated 27 years) $)^{3}$ and indicates a long period with inadequate treatment for patients with early-onset bipolar disorder, or that patients with a young age at onset have a slower symptom development or fewer characteristic symptoms.

The distribution of time to first treatment between age groups was much the same as in USA and European out-patients, ${ }^{3}$ illustrating that there is a problem treating patients early enough even in countries such as Norway, where everyone has access to health services.

A limitation of the study was that data were based on retrospective information from patients.

Age at onset of the first affective episode is much the same in Norwegian in-patients as in out-patients in the USA. Time from the first affective episode to the first pharmacological treatment and to the first hospital admission was inversely correlated with the age at first affective episode. This indicates a need for more focus on the early phases of bipolar disorder in psychiatric services.

\footnotetext{
Gunnar Morken, MD, PhD, Arne E. Vaaler, MD, PhD, Gunn E. Folden, MSC, Østmarka Psychiatric Department, St Olavs Hospital and Institute of Neuroscience, Norwegian University of Technology and Science, Trondheim; Ole A. Andreassen, MD, PhD, Department of Psychiatry, Ulleval University Hospital and Institute of Psychiatry, University of Oslo; Ulrik F. Malt, MD, PhD, Department of Neuropsychiatry and Psychosomatic Medicine, Division of Clinical Neurosciences, Rikshospitalet University Hospital and Institute of Psychiatry, University of Oslo, Norway.

Correspondence: Gunnar Morken, Østmarka Psychiatric Department, St Olavs Hospital, Box 3008 Lade, 7441 Trondheim, Norway. Email: gunnar.morken@ntnu.no

First received 7 May 2008, final revision 4 Aug 2008, accepted 1 Oct 2008
}

\section{References}

1 Post RM, Luckenbaugh DA, Leverich GS, Altshuler LL, Frye MA, Suppes T, et al. Incidence of childhood-onset bipolar illness in the USA and Europe. Br J Psychiatry 2008; 192: 150-1.

2 Leverich GS, Post RM. Course of bipolar illness after history of childhood trauma. Lancet 2006; 367: 1040-2.

3 Leverich GS, Post RM, Keck PE Jr, Altshuler LL, Frye MA, Kupka RW, et al. The poor prognosis of childhood-onset bipolar disorder. J Pediatr 2007; 150 485-90.

4 Geller B, Craney JL, Bolhofner K, Nickelsburg MJ, Williams M, Zimerman B. Two-year prospective follow-up of children with a prepubertal and early adolescent bipolar disorder phenotype. Am J Psychiatry 2002; 159: 927-33.

5 Perlis RH, Miyahara S, Marangell LB, Wisniewski SR, Ostacher M, DelBello MP, et al. Long-term implications of early onset in bipolar disorder: data from the first 1000 participants in the systematic treatment enhancement program for bipolar disorder (STEP-BD). Biol Psychiatr 2004; 55: 875-81.

6 Bennazzi F, Akiskal HS. How best to identify a bipolar-related subtype among major depressive patients without spontaneous hypomania: superiority of age at onset criterion over recurrence and polarity? J Affect Disord 2008; 107: 77-88.

7 Rihmer Z, Angst J. Mood disorders: epidemiology. In Kaplan \& Sadock's Comprehensive Textbook of Psychiatry (eds BJ Sadock \& VA Sadock): 1575-82. Lippincott Williams \& Wilkins, 2005.

8 American Psychiatric Association. Diagnostic and Statistical Manual of Mental Disorders (4th edn) (DSM-IV). APA, 1994.

9 First M, Spitzer R, Gibbon M, Williams J. Structured Clinical Interview for DSM-IV - Patient Version. American Psychiatric Press, 1997.

10 Post RM, Nolen WA, Kupka RW, Denicoff KD, Leverich GS, Keck PE Jr, et al. The Stanley Foundation Bipolar Network: I. Rationale and methods. Br J Psychiatry 2001; 178 (suppl 41): s169-76.

11 Suppes T, Leverich GS, Keck PE, Nolen WA, Denicoff KD, Altshuler LL, et al. The Stanley Foundation Bipolar Treatment Outcome Network: II. Demographics and illness characteristics of the first 261 patients. J Affect Disord 2001; 67: 45-59. 